Supporting Information

\title{
Mammalian Cell Surface Imaging with Nitrile-Functionalized Nanoprobes: Biophysical Characterization of Aggregation and Polarization Anisotropy in SERS Imaging

\author{
Qingyan $\mathrm{Hu}^{\dagger}$, Li-Lin Tay ${ }^{\ddagger}, \star$, Matthew Noestheden ${ }^{\dagger}$ and John Paul Pezacki ${ }^{\dagger, \star}$ \\ ${ }^{\dagger}$ Steacie Institute for Molecular Sciences, ${ }^{\dagger}$ Institute for Microstructural Sciences, National Research
} \\ Council Canada, Ottawa, Ontario, Canada K1A OR6
}

\section{Synthesis of Raman label 1}

General Methods. 4-Cyanophenylalanine was purchased from Chem Impex. All other chemicals were purchased from Sigma-Aldrich and used without further purification. Proton and carbon nuclear magnetic resonance $\left({ }^{1} \mathrm{H}\right.$ NMR) spectra were recorded using a Bruker AMX 400 spectrometer. High resolution mass spectra (HRMS) were obtained on a Bruker Daltonics APEXII 3 Tesla Fourier Transform Mass Spectrometer using electrospray ionization.<smiles>N#Cc1ccc(CC(N)C(=O)O)cc1</smiles>

2

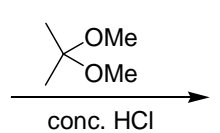

conc. $\mathrm{HCl}$
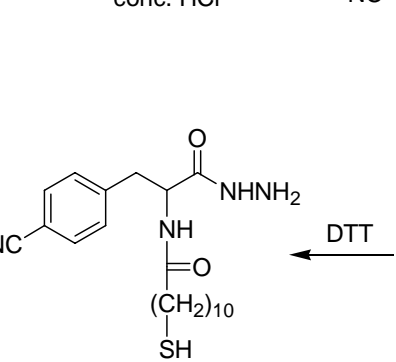

1

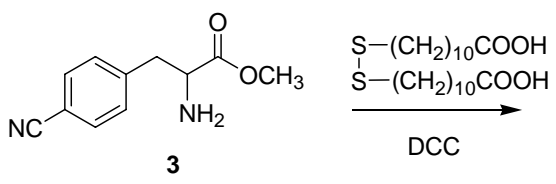

3

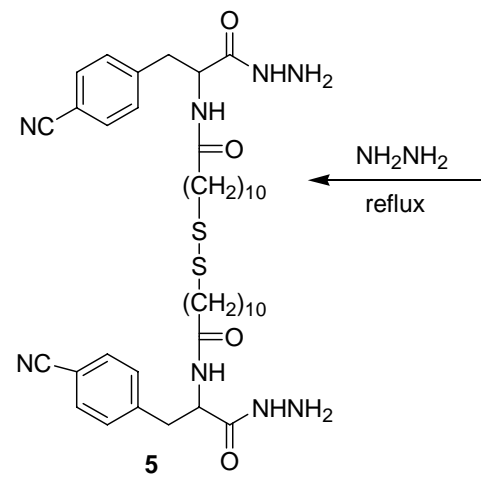

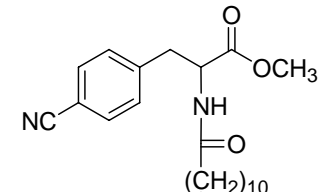

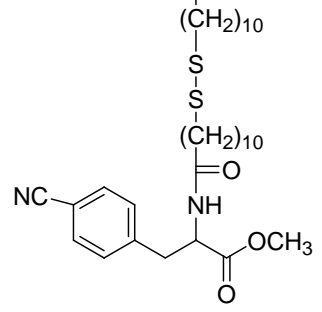

4

Synthesis of 4-nitrophenylalanine methyl ester 3

4-Nitrophenylalanine (2, $390 \mathrm{mg}, 2 \mathrm{mmol})$ was suspended in 2,2-dimethoxypropane (15 $\mathrm{ml})$ and then concentrated hydrochloric acid $(1 \mathrm{~mL})$ was added. The mixture was stirred at room temperature overnight. The volatile components were removed under reduced pressure. Ethyl acetate $(10 \mathrm{~mL})$ was added. The mixture was extracted by water $(15 \mathrm{~mL} \times$ 3 ) and the water layer was concentrate to give white solid $(438 \mathrm{mg}, 90 \%) .{ }^{1} \mathrm{H} \mathrm{NMR}$ $\left(\mathrm{D}_{2} \mathrm{O}, 400 \mathrm{~Hz}\right) \delta 7.67(\mathrm{~d}, 2 \mathrm{H}), 7.34(\mathrm{~d}, 2 \mathrm{H}), 4.36(\mathrm{dd}, 1 \mathrm{H}), 3.70(\mathrm{~s}, 3 \mathrm{H}), 3.26(\mathrm{dd}, 2 \mathrm{H})$.

Synthesis of $\mathbf{4}$ 
11-(10-Carboxy-decyldisulfanyl)-undecanoic acid (172mg, $0.4 \mathrm{mmol})$ and $180 \mathrm{mg}(0.88$ mmol) of DCC (dicyclohexylcarbodiimide) were suspended in $5 \mathrm{~mL}$ of dichloromethane. DMAP (4-dimethylaminopyridine, $30 \mathrm{mg}$ ) and a $2 \mathrm{~mL}$ dichloromethane solution with compound $3(204 \mathrm{mg}, 1.0 \mathrm{mmol})$ and triethylamine $(130 \mu \mathrm{L})$ were added. The mixture was stirred at room temperature overnight. The reaction mixture was then filtered and the filtrate was concentrated and purified on a silica column elude by ethyl acetate/hexane (8:2) to give $4(235 \mathrm{mg}, 73 \%) .{ }^{1} \mathrm{H}$ NMR $\left(\mathrm{CDCl}_{3}, 400 \mathrm{~Hz}\right) \delta 7.60(\mathrm{~d}, 4 \mathrm{H}), 7.24(\mathrm{~d}, 4 \mathrm{H})$, $5.96(\mathrm{~s}, 2 \mathrm{H}), 4.94(\mathrm{dd}, 2 \mathrm{H}), 3.76(\mathrm{~s}, 6 \mathrm{H}), 3.16(\mathrm{ddd}, 4 \mathrm{H}), 2.69(\mathrm{t}, 4 \mathrm{H}), 2.20(\mathrm{t}, 4 \mathrm{H}), 1.67$ $(\mathrm{m}, 8 \mathrm{H}), 1.30(\mathrm{~m}, 28 \mathrm{H}) .{ }^{13} \mathrm{C} \mathrm{NMR}\left(\mathrm{CDCl}_{3}, 100 \mathrm{MHz}\right) 173.1,172.1,142.2,132.6,130.5$, 119.0, 111.5, 53.1, 53.0, 39.5, 38.6, 36.9, 34.2, 29.9, 29.8, 29.7, 29.6, 28.9, 25.9, 25.3. EI-MS cacl'd for $\mathrm{C}_{44} \mathrm{H}_{63} \mathrm{~N}_{4} \mathrm{O}_{6} \mathrm{~S}_{2}: 807.4184$; found 807.4205

\section{Synthesis of 5}

Compound $4(100 \mathrm{mg}, 0.12 \mathrm{mmol})$ was added to a solution of hydrazine $(2 \mathrm{~mL})$ in ethanol $(5 \mathrm{~mL})$. The reaction mixture was heated and reflux for $5 \mathrm{~h}$. After cooling down, white precipitate formed and was filtered to get pure $5(78 \mathrm{mg}, 78 \%) .{ }^{1} \mathrm{H} \mathrm{NMR}\left(\mathrm{CDCl}_{3}\right.$, $400 \mathrm{~Hz}) \delta 7.60$ (d, 4H), 7.31 (d, 4H), $6.51(\mathrm{~s}, 2 \mathrm{H}), 4.75$ (dd, 2H), 3.12 (ddd, 4H), 2.65 (t, $4 \mathrm{H}), 2.16(\mathrm{t}, 4 \mathrm{H}), 1.62(\mathrm{~m}, 8 \mathrm{H}), 1.20(\mathrm{~m}, 28 \mathrm{H})$. EI-MS cacl'd for $\mathrm{C}_{42} \mathrm{H}_{63} \mathrm{~N}_{8} \mathrm{O}_{4} \mathrm{~S}_{2}$ : 807.4408 ; found 807.4384

\section{Synthesis of 1}

Compound 5 (30 mg, $37 \mu \mathrm{mol})$ was dissolved in $15 \mathrm{~mL} \mathrm{~N}$, N-dimethylformamide. Dithiothreitol (DTT, $7 \mathrm{mg}, 44 \mu \mathrm{mol}$ ) was added. The reaction mixture was stirred at room temperature under argon for overnight to get compound 1. EI-MS cacl'd for $\mathrm{C}_{21} \mathrm{H}_{33} \mathrm{~N}_{4} \mathrm{O}_{2} \mathrm{~S}$ : 405.2319; found 405.2320

\section{Preparation of citrate-protected silver nanoparticles (Ag-NPs)}

Citrate-reduced Ag-NPs were prepared according to Smith procedure. ${ }^{1}$ All glassware was thoroughly cleaned with aqua regia and rinsed with Millipore-Q water prior to use. Approximately $150 \mathrm{~mL}$ Millipore-Q water was placed in a clean $250 \mathrm{~mL}$ round-bottomed flask. The water was heated to $45^{\circ} \mathrm{C}$, at which point $45 \mathrm{mg}$ of silver nitrate was added. Keep heating until water began to reflux. $5 \mathrm{~mL} 1 \%$ trisodium citrate was added and the mixture was kept refluxing for 90 min. Cool down while keep stirring, the nanoparticles were centrifuged at $4000 \mathrm{rpm}$ for $20 \mathrm{~min}$. Decant top liquid, the silver nanoparticles were dialyzed against Millipore-Q water for $48 \mathrm{~h}$ before ready to use. The final volume of the nanoparticles was $60 \mathrm{~mL}$. The concentration of the nanoparticles was estimated by Smith method $^{2}$ to be $1 \mathrm{nM}$. The diameter of the nanoparticles was measured to be $60 \pm 15 \mathrm{~nm}$ by Zetasizer 300 . 


\section{Synthesis of Ag-NP-1}

Citrate-coated silver nanoparticles $(159 \mu \mathrm{L})$ prepared above was suspended in $650 \mu \mathrm{L}$ water and $190 \mu \mathrm{L}$ DMF. $1 \mu \mathrm{L}$ of compound $1(0.1 \mathrm{mM}$ stock solution in 1:1 DMF/water) was added. The reaction mixture was stirred for $60 \mathrm{~min}$ at room temperature and then dialyzed against Millipore-Q water for $48 \mathrm{~h}$. The UV-Vis and SERS spectra of the resulting silver nanoparticle (Ag-NP-1) are shown below. Note that the SERS spectrum was obtained with a power density two orders of magnitude lower than those used in the imaging experiments.
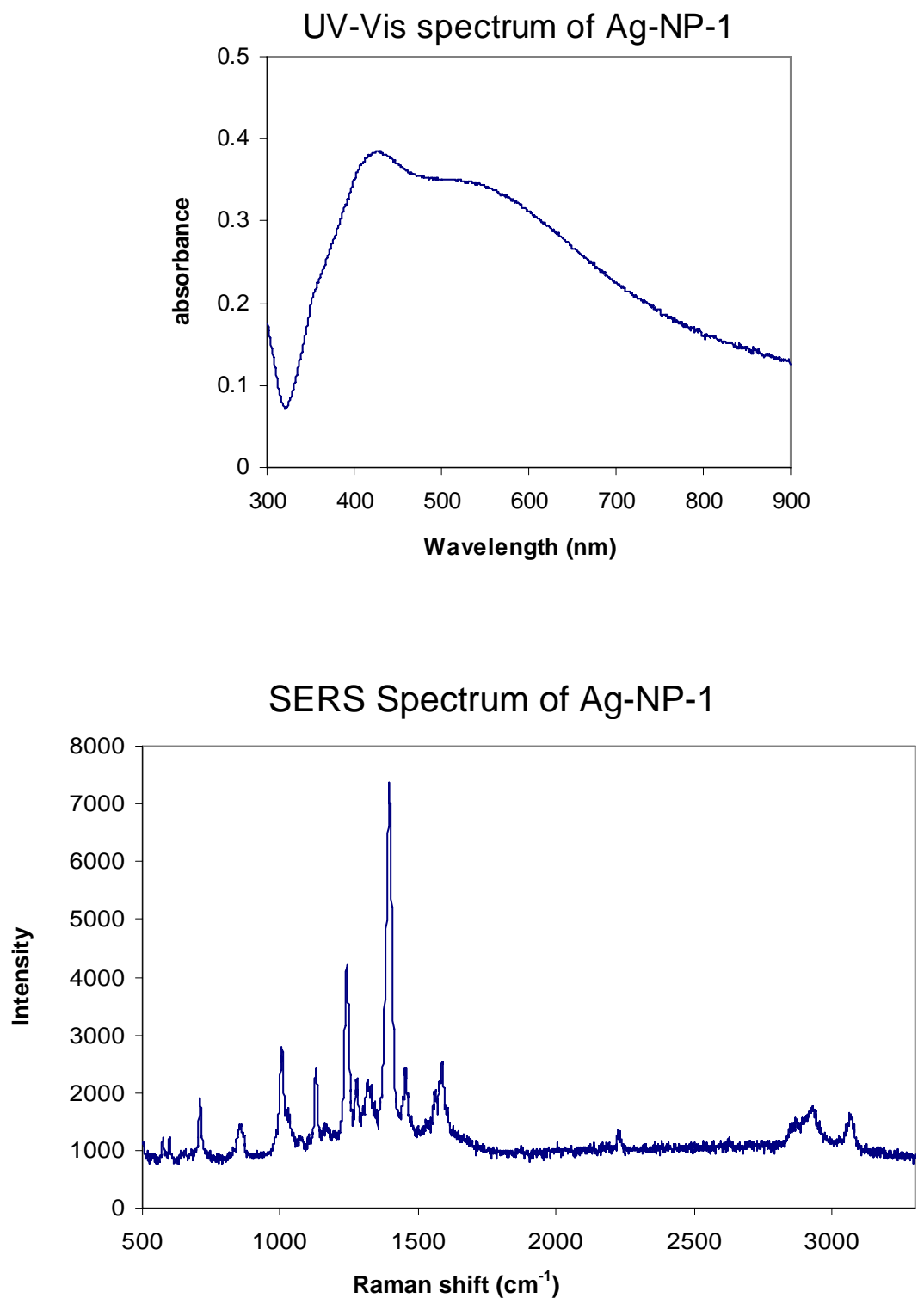


\section{Cell surface protein expression and labeling with Ag-NP-1}

Construct AP-CFP-TM ${ }^{3}$ (AP, accept peptide, fused to the $\mathrm{N}$ terminus of of CFP, cyano fluorescent protein, and then attached to TM, transmembrane domain of the plateletderived growth factor receptor) was expressed in HeLa cells on silicon surface spincoated with collagen $24 \mathrm{~h}$ after transfection. Ketone 1 (biotin analogue, structure shown below) was efficiently incorporated to AP by bacterial BirA enzyme ( $5 \mathrm{mM} \mathrm{MgCl}_{2}, 0.2$ $\mu \mathrm{M}$ BirA, $1 \mathrm{mM}$ racemic ketone 1 and $1 \mathrm{mM}$ ATP in PBS, pH 7.4 for $60 \mathrm{~min}$ at $\left.32^{\circ} \mathrm{C}\right){ }^{3}$ The cells were washed with $3 \times 50 \mu \mathrm{L}$ PBS and then incubated with $20 \mu \mathrm{l}$ of Ag-NP-1 colloid solution (prepared above) in $20 \mu \mathrm{HeLa}$ medium with serum at $16{ }^{\circ} \mathrm{C}$ for an hour. The cells were then fixed with $3.7 \%$ formaldehyde in PBS and washed six times with water and dried in ambient condition.

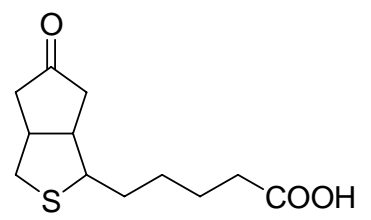

\section{Structure of ketone 1}

\section{Raman Spectroscopy and Microscopy}

All Raman scattering experiments were conducted with microRaman (Horiba J.Y. LabRam HR) with $632 \mathrm{~nm}$ excitation and power density of $10^{4} \mathrm{~W} / \mathrm{cm}^{2}$. Incident radiation is tightly focused by a $100 \mathrm{X}(\mathrm{Na}=0.90)$ objective onto the sample. Imaged samples were rastered under microscope and full Raman spectra were collected from a set of grid points separated $0.5 \mu \mathrm{m}$ apart. Upon completion, the intensity map of a specific vibrational band was generated by extrapolating the integrated intensity under the Raman band with the background fitted and removed. All Raman spectra were observed with 1 second integration time.

Cell imaging using Raman spectromicroscopy has been demonstrated to reveal different cellular components, where as the SERS imaging relies on the presence of the labeled silver nanoparticles to act as the nanoscale indicators for the presence of the expressed protein in the transfected cell. Raman spectra obtained from spots I and II (Fig. 1b) are very similar and all contain the typical cellular Raman bands: amide I $\left(1660 \mathrm{~cm}^{-1}\right)$, amide III (1285 and $\left.1350 \mathrm{~cm}^{-1}\right), \mathrm{CH}\left(2990 \mathrm{~cm}^{-1}\right)$, and $\mathrm{CH}\left(1447 \mathrm{~cm}^{-1}\right)$ vibrations. Where as the region around spot III (Fig. 1b) is likely over of the nucleus, its cellular Raman spectra contain two additional bands due to a higher concentration of nucleic acid (1090 and $1580 \mathrm{~cm}^{-1}$ ). In contrast, the SERS spectra obtained from Ag-NP rich regions of spot I, II and III all revealed the distinct $\mathrm{C} \equiv \mathrm{N}$ vibrational band at $2230 \mathrm{~cm}^{-1}$ as shown in Fig. 1(b) in the manuscript. 


\section{SERS enhancement factor}

SERS enhancement factor (EF) can be estimated by comparing the intensity of the $\mathrm{C} \equiv \mathrm{N}$ band from the SERS experiment to the intensity of the same band obtained from the bulk Raman measurements. The bulk Raman experiment was performed on a $5 \mathrm{mM}$ dimethylformamide (DMF) solution. SERS EF can be expressed as ${ }^{4}$

$$
E F=\left(\frac{I_{\text {SERS }}}{I_{\text {bulk }}}\right)\left(\frac{N_{\text {bulk }}}{N_{\text {SERS }}}\right)
$$

Where $N_{\text {bulk }}$ and $N_{\text {SERS }}$ are the number of probe molecules in the bulk DMF solution and on the NP surfaces, respectively, that were probed by the incident laser beam. $I_{b u l k}$ and $I_{S E R S}$ are the corresponding bulk and SERS $\mathrm{C} \equiv \mathrm{N}$ band intensity normalized to the same laser power and acquisition time. Bulk Raman was obtained by illuminate a $45 \mu \mathrm{L}$ microcuvette cells with an optical path length of $3 \mathrm{~mm}$. Collimated laser beam with a beam diameter of $0.8 \mathrm{~mm}$ was guided onto the sample through a macro-attachment. Thus, the probe volume for the bulk Raman measurement is approximated as a cylinder with a radius of $0.4 \mathrm{~mm}$ and height of $3 \mathrm{~mm}$, resulting in $4.5 \times 10^{12}$ molecules being probed $\left(N_{\text {bulk }}\right)$. Although the SEM and Raman correlation studies allows us to accurately estimate the number of NPs under laser illumination at the obtained SERS hot-sites, we can only offer a conservative estimate on the number of probe molecules on these NPs. Because the probe molecule is novel and synthesized specifically for this study, its packing density on the metal surface has not been characterized. From the literature, alkyl thiols typically have packing density of $10^{14}$ molecules $/ \mathrm{cm}^{2}$; e.g. $6.8 \times 10^{14}$ for benzenethiol ${ }^{5}$ and $2.7 \times 10^{14}$ for aminothiolphenyl. ${ }^{6}$ To offer a conservative $N_{\text {SERS }}$ estimate, we approximate the packing density of the used Raman probe to be similar to that of aminothiolphenyl, eventhough, the actual number is probably less because of the larger molecular structure and more pronounced steric effect from the probe molecule. This estimate will provide us a lower bound for the SERS EF factor. Using spot I (Fig. 2(f)) as an example, there were 4 NPs illuminated by the laser beam. The NPs have average dimension of $60 \mathrm{~nm}$. Thus, approximately $1.2 \times 10^{5}\left(\mathrm{~N}_{\mathrm{SERS}}\right)$ molecules were probed in spot I. Substituting both $N_{\text {SERS }}$ and $N_{\text {bulk }}$ as well as the normalized $I_{S E R S}$ and $I_{\text {bulk }}$ into the EF equation above results in a SERS $E F$ of $\sim 10^{10}$. 


\section{Polarization anisotropy in SERS imaging}

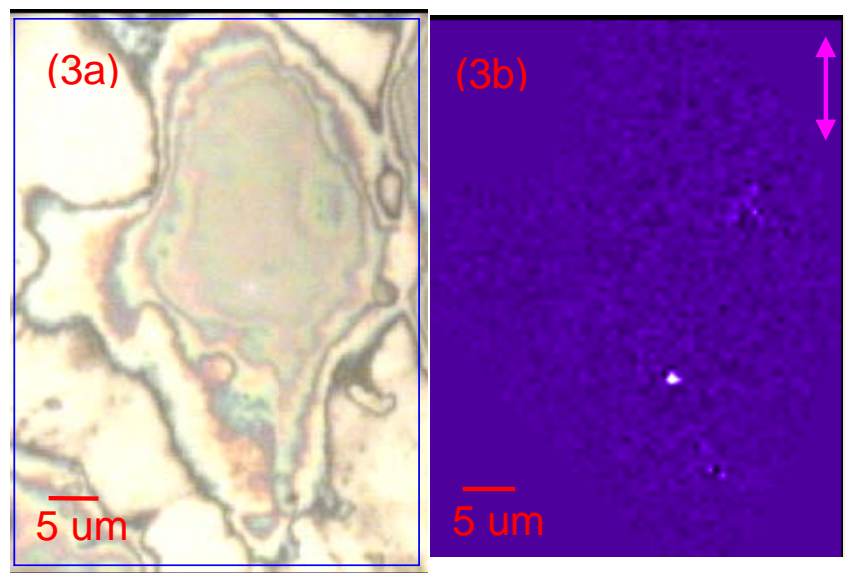

Figure 3 (a) Optical image of the same HeLa cell depicted in Fig. 1(c). (b) The corresponding intensity map of the $\mathrm{CN}$ vibrational band. Pink arrow indicates the direction of incident light polarization. The bright spot corresponds to NP aggregate I in Fig. 1(c).

If the size of the NPs is much smaller than the excitation wavelength of the electromagnetic field, the polarized conduction electrons can be approximated as an oscillating plasmonic dipole. In a coupled dimer configuration, two interacting plasmonic dipole are allowed to couple when the incident light is polarized parallel to the interparticle axis. Molecules sandwiched in the tight interstitial gap between two coupled dimer will experience field intensity which greatly exceeds that generated by individual plasmonic dipole alone. Theoretical calculations from Matiu and Kall have shown that an enhancement factor of $10^{11}$ to be attainable with a tight interstitial gap of $1 \mathrm{~nm} .^{7-11}$ On the other hand, if the dimers were excited with light polarized perpendicular to the interparticle axis, the field is excluded from the gap region resulting in no enhancement at all. This strong polarization anisotropy in small NP aggregates is demonstrated in Fig. 3. We rotated the sample by $90^{\circ}$ (Fig. 1(c)) and imaged the same cell with Raman spectrometer. Intensity image of the $\mathrm{CN}$ vibrational band (Fig. 3(b)) was obtained with the same power level, acquisition time and polarization as those generated in Fig. 1(d). In Fig. 1(d) three intense CN modes were observed and correlated to NPs aggregates labeled as I, II and III. There is only one intense CN vibration mode was observed in Fig. 3(b). From the location of the observed intense spot in Fig. 3(b), one can immediately conclude that the spot III is no longer a SERS hot site. In addition, aggregate II (Fig. 1(f)) took on a near-linear geometry with its interparticle axis close to perpendicular of the incident polarization as indicated in Fig 3(b). The NPs in spot I were arranged in a more random fashion which is likely to have plasmonic dipolar coupling in both of the sampled polarizations. Therefore, the intense SERS spot generated in Fig. 3(b) is probably from NP aggregate I of Fig. 1(f). In general, one almost always expect that larger NPs aggregates that is composed of NPs arranged in a random fashion to exhibit more polarization isotropy compared to those that took on linear shape or the isolated dimer particles. $^{12}$ 


\section{References}

(1) Keir, R.; Sadler, D.; Smith, W. E. Appl. Spectrosc. 2002, 56, 551-559.

(2) Jones, J. C.; McLaughlin, C.; Littlejohn, D.; Sadler, D. A.; Graham, D.; Smith, W. E. Anal. Chem. 1999, 71, 596-601.

(3) Chen, I.; Howarth, M.; Lin, W.; Ting, A. Y. Nat. Methods 2005, 2, 99-104.

(4) Van Duyne, R. P. In Chemical and Biochemical Applications of Lasers; Moore, C.B., Ed.; Academic Press: New York, 1979; Vol. 4, 101-184.

(5) McFarland, A. D.; Young, M. A.; Dieringer, J. A.; Van Duyne, R. P.; J. Phys. Chem. B 2005, 109, 11279-11285.

(6) Mohri, Inoue, M.; Arai, Y.; Langmuir, 1995, 11, 1612-1616.

(7) Aravind, P. K.; Nitzan, A. Metiu, H. Surf. Sci. 1981, 110, 189-204.

(8) Aravind, P. K.; Metiu, H. J. Phys. Chem. 1982, 86, 5076-5084.

(9) Aravind, P. K.; Metiu, H. Surf. Sci. 1983, 124, 506-528.

(10) Xu, H. X.; Kall, M. Chem. Phys. Chem. 2003, 3, 1001-1005.

(11) Xu, H. X.; Aizpurua, J.; Kall, M. Phys. Rev. B 2000, 62, 4318-4324.

(12) Kall, M; Xu, H. X.; Johansson, P; J. Raman Spectrosc. 2005, 36, 510-514. 